\title{
Erratum: Pharmacokinetics of Digoxin: Comparison of a Two- and a Three-Compartment Model in Man
}

William G. Kramer, Richard P. Lewis, Tyson C. Cobb, Wilbur F.

Forester, Jr., James A. Visconti, Lee A. Wanke, Harold G. Boxenbaum, and Richard $H$. Reuning

In this report (Vol. 2, No. 4, 1974, pp. 299-312), equation 10 on p. 302 is printed incorrectly as follows:

$$
\theta=\arccos \left[-\frac{b}{2}+\left(\frac{-a^{3}}{27}\right)^{1 / 2}\right]
$$

The correct form should read:

$$
\theta=\arccos \left[-\frac{b}{2} \div\left(\frac{-a^{3}}{27}\right)^{1 / 2}\right]
$$

with a division sign replacing the addition sign. 